\title{
THE ROLE OF CERTAIN MICROBIAL METABOLITES AS SPECIFIC COMPLEXING AGENTS
}

\author{
V. Prelog
}

Organisch-chemisches Laboratorium ETH, Zürich, Switzerland

\begin{abstract}
The discovery of microbial metabolites-macrotetrolides, siderochromes and boromycin-is reviewed. The structures of these and related compounds provide instructuve examples of how Nature has solved the problem of complexing certain rarer elements, such as potassium, iron and boron. The common structural features of these highly specific, natural complexing agents are briefly discussed.
\end{abstract}

It was emphasized by Academician M. M. Shemyakin in his opening lecture ${ }^{1}$ and it was confirmed explicitly or implicitly by all following plenary lecturers that the chemistry of natural compounds has changed considerably in the 'sixties from descriptive natural history of individual compounds towards a bioorganic chemistry that overlaps with biochemistry and molecular biology. We believe today that in the structure of natural compounds we find wisdom collected by living matter during several hundred millions of years. Natural compounds are the result of hundreds of millions of years of chemical experimentation of living organisms controlled by evolution and perhaps other hitherto undiscovered factors. In spite of the great progress in understanding biological phenomena on a molecular basis, we still do not know most of the essential structural details of natural biological tools. We can therefore still learn a great deal by investigating natural compounds. By doing so we shall not perhaps reach the level of the supreme wisdom, but the results can serve as a useful starting point in the terrifying multidimensional space of research possibilities in biological sciences. One fascinating research subject in this respect is the study of the specific complexing agents by which organisms concentrate within their bodies elements that are essential for life but occur in Nature either accompanied by a large excess of similar elements (e.g. potassium), or are widely spread but in low concentrations (e g. boron, cobalt, copper, iron, molybdenum, zinc etc).

In what form do organisms bring these elements in the right concentrations at the right time to the right place, i.e. to the interior of the cell or its subunits, where they are needed? I would like to illustrate this question by a few examples found by investigating microbial metabolites by a research 
team working at the Organic Chemistry Laboratory and the Institute of Special Botany at the ETH in Zürich and Research Laboratories of CIBA Ltd in Basel. Because of the limited time at my disposal I have to concentrate almost exclusively on the work from these Swiss laboratories, mentioning the results from other places only marginally when they are relevant to our work. I am aware of the fact that by doing so I shall give you a very unbalanced picture. I feel this especially with respect to the extremely valuable extended work on polypeptides and depsipeptides of our hosts, the research team working in the Institute for Chemistry of Natural Products of the Academy of Science in Moscow under the leadership of M. M. Shemyakin and $\mathrm{Yu}$. A. Ovchinnikov. Fortunately some results of these investigations have been mentioned in several other plenary lectures and also by Academician Shemyakin himself. To do justice to this work alone would demand more time than I have altogether. The same reason forbids even touching the most important old champions among the natural complexing agents, porphyrins and corrins. I shall also not discuss the biologically very interesting iron(III) complexes from Mycobacteria, mycobactins, investigated and elucidated by G. A. Snow et al. ${ }^{2}$ and copper complexes from Actinomyces, phleomycins and bleomycins, isolated by $\mathrm{H}$. Umezawa et al. ${ }^{3}$. I shall concentrate on some microbial metabolites investigated in our laboratories that are highly specific complexing agents for potassium ions, iron(III) ions, and boric acid.

\section{MACROTETROLIDES AS SPECIFIC COMPLEXING AGENTS FOR POTASSIUM ION ${ }^{4}$}

During the last few years several antibiotics have been found that are specific complexing agents for potassium ion. A list of these antibiotics is shown in Table 1. They are either neutral polypeptides and depsipeptides (such as valinomycin, Figure 1) or macrotetrolides, or else polyether carboxylic acids (such as nigericin, Figure 2).

Table 1. Antibiotics, complexing agents for alkali metal ions

\begin{tabular}{ll}
\hline Valinomycin & Nigericin \\
Gramicidins A, B, C, S & Monensin \\
Enniatins A, B & Dianemycin \\
Macrotetrolides &
\end{tabular}

It is perhaps instructive to recapitulate from our point of view the historical sequence of events. In the early 'fifties we isolated first one, and later several other antibiotics of macrotetrolide group and elucidated their structure in the early 'sixties ${ }^{4}$. The four main representatives have been named by us nonactin, monactin, dinactin and trinactin. Their empirical formulae and some properties are shown in Table 2. The structure of these compounds illustrated by the general constitutional formula (Figure 3 ) was determined mainly by investigation of the constitution and configuration of the hydroxyacids formed by hydrolysis and of the diols formed by lithium aluminium 
hydride reduction of the antibiotics. The main feature of the structure, the large 32-membered tetralactone ring, is expressed by the generic name macrotetrolides. Our experts considered these antibiotics to be very weak and to have low toxicity. The reason for this wrong conclusion was their

D-Hy-i-Valac D-Val L-Lac L-Val

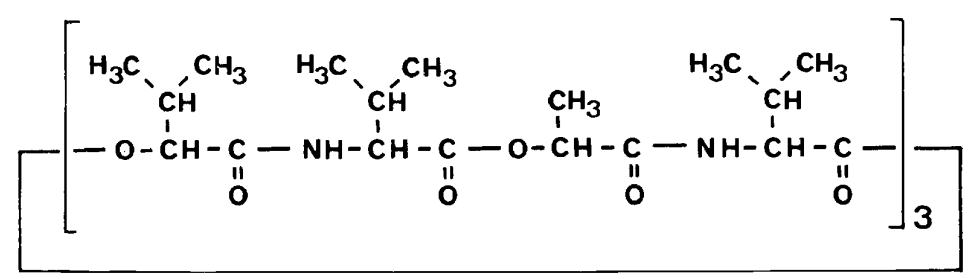

Figure 1. Valinomycin.

high lipophilicity and low solubility in aqueous solvents. D. Pearlman at Squibb Laboratories, New Brunswick, was the first to emphasize that they are highly toxic for cell cultures and to higher organisms when applied properly, $\mathbf{H}$. Lardy et al. ${ }^{5}$ then showed the reason for this toxicity: the macrotetrolides are very potent inhibitors of oxidative phosphorylation and

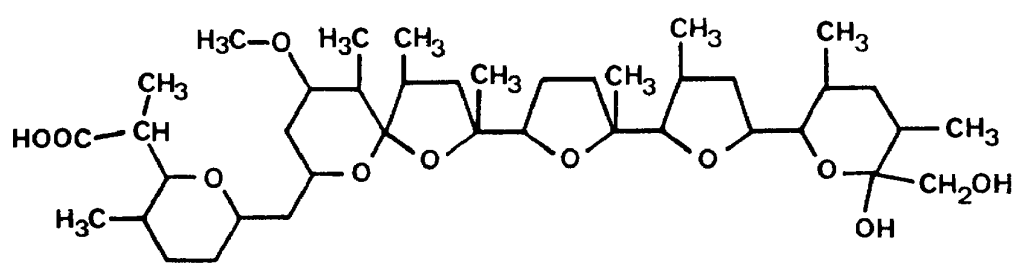

Figure 2. Nigericin.

activators of ATP hydrolases. B. C. Pressman et al. ${ }^{6}$ have in the meantime investigated the swelling effect of several of the antibiotics listed in Table 1 and related synthetic compounds on rat liver mitochondria. All these and some other biological effects could be attributed to the active or passive

Table 2. Macrotetrolides

\begin{tabular}{lrlcl}
\hline & M. pt & & {$[\alpha]_{D}$} & $R f$ \\
\hline Nonactin & $148^{\circ}$ & $\mathrm{C}_{40} \mathrm{H}_{64} \mathrm{O}_{12}$ & $0^{\circ}$ & 0.62 \\
Monactin & $64^{\circ}$ & $\mathrm{C}_{41} \mathrm{H}_{66} \mathrm{O}_{12}$ & $+2^{\circ}$ & 0.48 \\
Dinactin & $67^{\circ}$ & $\mathrm{C}_{42} \mathrm{H}_{68} \mathrm{O}_{12}$ & $+2.5^{\circ}$ & 0.32 \\
Trinactin & $68^{\circ}$ & $\mathrm{C}_{43} \mathrm{H}_{70} \mathrm{O}_{12}$ & $+1.5^{\circ}$ & 0.15 \\
& & & & \\
\hline
\end{tabular}

potassium ion transport through biological membranes. Many of the compounds for this research were supplied by M. M. Shemyakin, Yu. A. Ovchinnikov et al., who also studied their topography and other relevant properties. 


\section{PRELOG}

W. Simon et al. ${ }^{7}$ in our laboratory were first to demonstrate in 1966 the specific transport of potassium ions through artificial membranes made from macrotetrolides on inert support. The electrochemical cells constructed with such membranes show a high specificity for potassium ions, relative to other alkali metal ions, which parallels the activation of ATP hydrolase

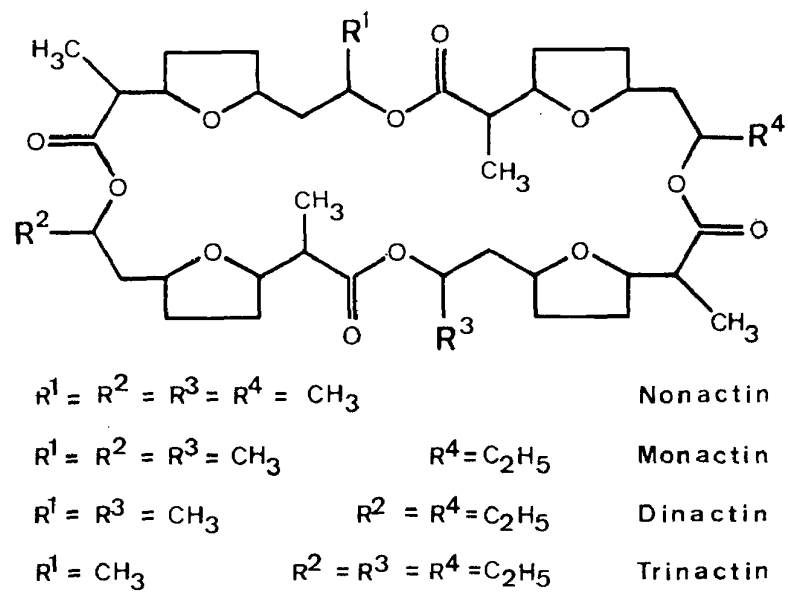

Figure 3. Macrotetrolides.

activity as determined by $\mathrm{H}$. Lardy et al. This was confirmed by elegant experiments of P. Müller and D. O. Rudin ${ }^{8}$ on bilayer phospholipid membranes, which become highly conductive in the presence of these antibiotics and potassium ions. W. Simon et al. also determined the stability constants of alkali metal complexes of macrotetrolides ${ }^{9}$ and prepared several of them in crystalline form ${ }^{10}$. The difference between the stability constants of the complexes of sodium and potassium shown in Table 3 explains the significantly higher biological activity of the latter.

Table 3. Stability constants $K$ of macrotetrolide- $\mathrm{M}^{+} \mathrm{CNS}^{-}$complexes in methanol at $30^{\circ}$

\begin{tabular}{|c|c|c|c|}
\hline \multirow[b]{2}{*}{ Macrotetrolide } & \multicolumn{2}{|c|}{$K$ in $1 / \mathrm{Mol}$ for $\mathbf{M}^{+}$} & \multirow{2}{*}{$\frac{K_{\mathbf{K}+}}{K_{\mathrm{Na}+}}$} \\
\hline & $\mathrm{Na}^{+}$ & $\mathrm{K}^{+}$ & \\
\hline $\begin{array}{l}\text { Nonactin } \\
\text { Monactin }\end{array}$ & $\begin{array}{l}(1.3 \pm 0.2) \times 10^{2} \\
(1.1 \pm 0.1) \times 10^{3}\end{array}$ & $\begin{array}{l}(5.0 \pm 0.7) \times 10^{3} \\
(2.5 \pm 1.0) \times 10^{5}\end{array}$ & $\begin{array}{r}38 \pm 5 \\
230 \pm 70\end{array}$ \\
\hline
\end{tabular}

The structure of the crystalline nonactin potassium thiocyanate complex, determined in our laboratory by J. D. Dunitz et al. ${ }^{11}$, revealed some very interesting features which can be seen in Figure 4. The potassium ion is situated at the centre of an almost regular cube, the eight vertices being occupied by four carbonyl and four tetrahydrofuran oxygens. The 32membered ring of the macrotetrolide forms a closed curve which resembles the seam of a tennis ball with potassium at its centre. The structure partially 


\section{MICROBIAL METABOLITES - SPECIFIC COMPLEXING AGENTS}

explains the ion specificity. The potassium ion fits almost exactly into the central hole formed when the atoms of the complexed macrotetrolide are optimally distributed. A small ion like lithium is not large enough to fill the hole and a large ion like caesium would require deviations from the optimal conformation.

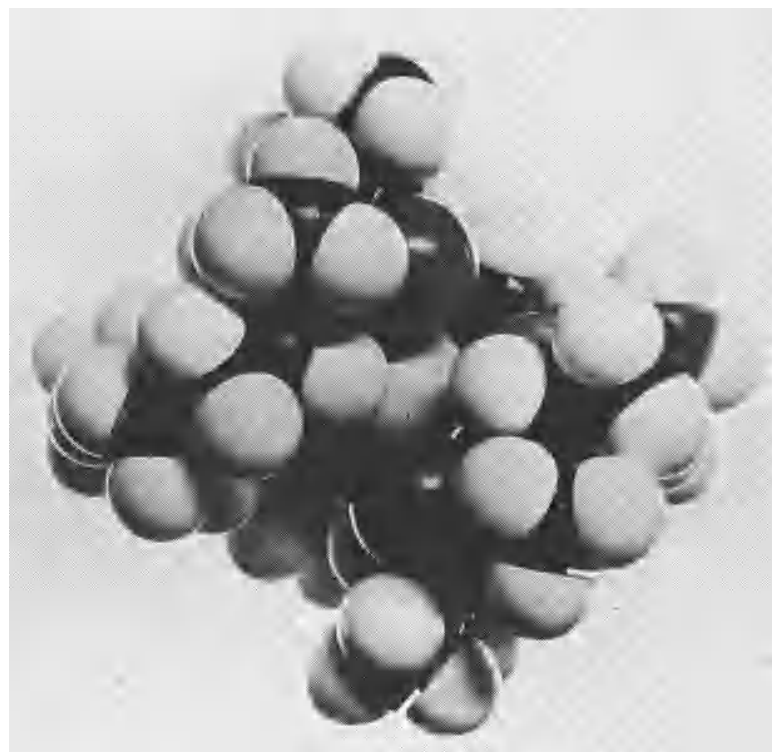

Figure 4. Nonactin-potassium ion complex.

The rates of formation of macrotetrolide complexes with alkali metal ions have been measured by $\mathrm{M}$. Eigen et al. using relaxation methods ${ }^{12}$. The rates are unexpectedly fast, approaching the diffusion rate. All these properties make the macrotetrolides very instructive models for studies of the actual ion carriers that play such an important role in biological phenomena.

Some recent work of W. Simon et al. in our laboratory confirms that point of view. In electrolysis experiments using radioactive sodium and potassium ions on the anodic side of an artificial membrane consisting of macrotetrolide on an inert carrier, practically only potassium ions are transported through the membrane ${ }^{13}$. By using membranes made of several layers of which the one on the anodic side of the electrolytic cell contains radioactive macrotetrolide or valinomycin it can be demonstrated that there is a $1: 1$ relation between the transported ion and antibiotic. An interesting mechanistic difference between the two antibiotics could be observed by careful evaluation of these experiments. Valinomycin seems to be a free carrier of the ion whereas the macrotetrolide is a relay carrier ${ }^{14}$.

A practical use of the artificial antibiotic membranes as ion-specific sensors for determination of potassium in the presence of sodium and other 
alkali metal ions can be only mentioned here. The antibiotic valinomycin is so far the best material for the construction of such sensors ${ }^{15}$.

C. J. Pedersen et al. ${ }^{16}$ have prepared a great number of synthetic macrocyclic polyethers called by them 'crowns', and J. M. Lehn et al. ${ }^{17}$ have synthesized macrobicyclic diazapolyethers which they call 'cryptates'. These compounds are as powerful complexing agents for alkali metal and other ions as the natural polyethers. Such synthetic agents - -besides being potential models for biochemical ion-carriers and potential building material for ionspecific sensors-have also other applications, for example, as anion activators.

\section{SIDEROCHROMES, STABLE NATURAL IRON (III) TRIHYDROXAMATE COMPLEXES ${ }^{18,19}$}

In the course of the search for new antibiotics a red-brown highly active iron-containing antibiotic was detected in our laboratories. We called it ferrimycin. Our efforts to isolate it in a pure state were initially marred by the erratic disappearance and reappearance of its antibiotic activity. The explanation for this behaviour was unexpected but simple. The crude antibiotic was accompanied by compounds that are its antagonists! Moreover, the antibiotic is converted under very mild conditions into compounds which are also its antagonists. After this discovery it was easy to detect the presence, or rather the excess, either of the antibiotics or their antagonists by a simple microbiological 'antagonism test' which can be used under standardized conditions also for quantitative determinations of both the antibiotics and their antagonists (cf. Figure 1 in ref. 19). Scrutiny of the literature revealed that similar iron-containing antibiotics had been isolated before: one called grisein by S. Waksman, the pioneer in the field of antibiotics from Streptomyces, a closely related one called albomycin by G. F. Gause and M. G. Brazhnikova. These antibiotics behave towards antagonists isolated in our laboratory in the same way as ferrimycin. We also learned that several iron-containing growth factors called ferrichrome, coprogen, and terregens factor had previously been detected and isolated by J. B. Neilands, C. W. Hesseltine, A. G. Lochhead and their respective coworkers. It could be shown by the 'antagonism test' that these growth factors are also antagonists for the iron-containing antibiotics and by the 'growth factor activity test' that the antagonists isolated in our laboratory are also microbial growth factors (cf. Figure 2 in ref. 19).

All these antibiotics and growth factors show a broad absorption band with a maximum at $460 \mathrm{~nm}$, which is typical for the common feature in their structures. They are all trihydroxamate complexes of iron(III) ion. We have given all these compounds the generic name siderochromes. The siderochromes with a pronounced antibiotic activity we call sideromycins and those which are growth factors sideramines. There are also siderochromes such as ferrichrome A without any detectable biological activity. A list of siderochromes is given in Table 4. The detailed structures of most of these compounds have now been elucidated in our laboratories and by J. B. Neilands and T. Emery. The results have been confirmed by unambiguous syntheses carried out in our laboratory. The structure of ferrichrome A has 
Table 4. Siderochromes

\begin{tabular}{llll}
\hline \multicolumn{2}{c}{ Sideramines } & Sideromycins & \\
\hline $\begin{array}{l}\text { Ferrichrome } \\
\text { Coprogen }\end{array}$ & Ferrioxamine A & Grisein & Ferrichrome A \\
Terregens Factor & Ferrioxamine B & Albomycin S & \\
& Ferrioxamine C & & \\
Ferrichrysin & Ferrioxamine $D_{1}$ & Ferrimycin A & \\
Ferricrocin & Ferrioxamine $D_{2}$ & Ferrimycin A & \\
Ferrirhodin & Ferrioxamine E & Ferrimycin B & \\
Ferrirubin & Ferrioxamine G & Succinimycin & ETH 22 765 \\
Fusarinines & & LA 5352 \\
Fusigen & & LA 5937 & \\
\hline
\end{tabular}

also been confirmed by $\mathrm{x}$-ray analysis. Without discussing the details of all this extensive work I shall merely show its end-result. Three different structural types have been found. Iron-free complexing agents of sideramines from cultures of Streptomyces strains called ferrioxamines (Figures 5, 6) are either long chains or large rings containing three bidentate hydroxamate

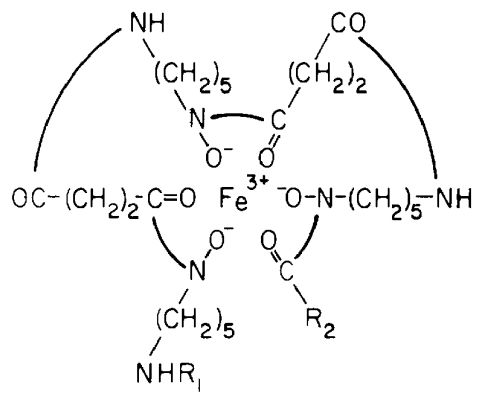

Ferrioxamine $B$

$\mathrm{R}_{1}=\mathrm{H} \quad \mathrm{R}_{2}=\mathrm{CH}_{3}$

Ferrioxamine $D_{1}$

$\mathrm{R}_{1}=\mathrm{CH}_{3} \mathrm{CO} \quad \mathrm{R}_{2}=\mathrm{CH}_{3}$

Ferrioxamine $G$

$\mathrm{R}_{1}=\mathrm{H} \quad \mathrm{R}_{2}=\mathrm{CH}_{2} \mathrm{CH}_{2} \mathrm{COOH}$

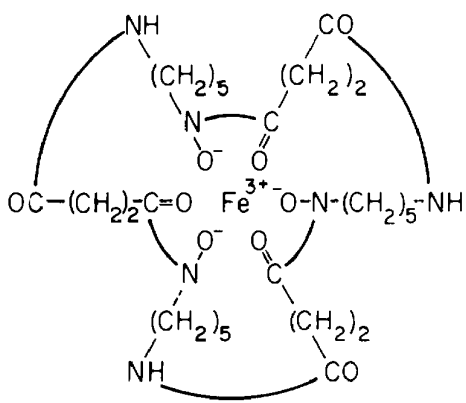

Ferrioxamine $E$

Figure 5. Sideramines from Actinomyces.

groups in a linear sequence. Complexing agents derived by removal of iron(III) from ferrichrome, ferrichrysin, ferricrocin, ferrirhodin, and ferrirubin (Figure 7)-all siderochromes from Fungi-are cyclohexapeptides with a large ring carrying three side chains with bidentate hydroxamate groups. To a slightly different third structural type belong some sideramines from Fusaria (Figure 8). The complexing agents of these compounds are either depsipeptides, as in fusarinine $\mathrm{B}^{20}$, or cyclodepsipeptides, as in fusigen ${ }^{21}$, built from the same components as the sideramines from Fungi. Related to 


\section{PRELOG}



Ferrioxamine $\mathrm{A}$ $m=4, n=5$ or $m=5, n=4$

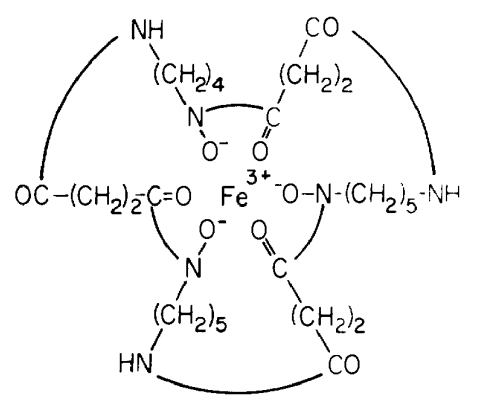

Ferrioxamine $D_{2}$

Figure 6. Sideramines from Actinomyces.



$\mathrm{A}=\mathrm{B}=\mathrm{C}=\mathrm{gly} \quad \mathrm{R}=\mathrm{CH}_{3}$ Ferrichrom
$A=$ gly,$B=C=L-$ ser

$$
\begin{gathered}
\mathrm{R}=\mathrm{CH}_{3} \\
\text { Ferrichrysin }
\end{gathered}
$$

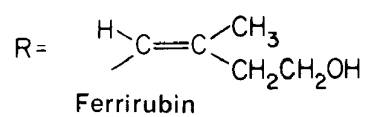

$R=$<smiles>CC=C(C)CCO</smiles>

Ferrirhodin<smiles>[R][CH]/C(C)=C(/C)CC(=O)O</smiles>

Ferrichrom A

\section{$A, B, C,=\underset{\text { Ferricrocin }}{2 \mathrm{gly}, I \text {-ser }} \mathrm{R}=\mathrm{CH}_{3}$}

Figure 7. Siderochromes from Fungi.

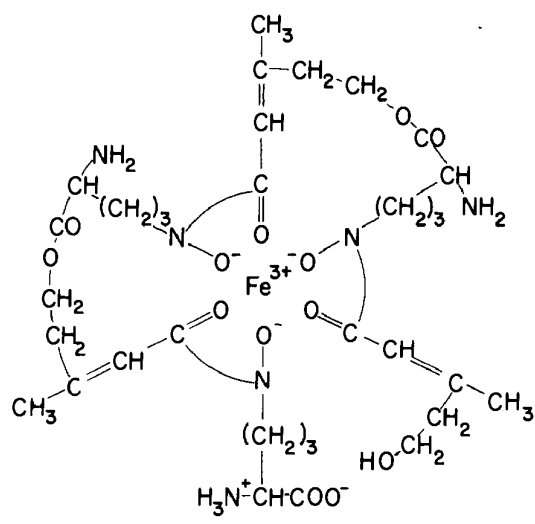

Fusarinine B

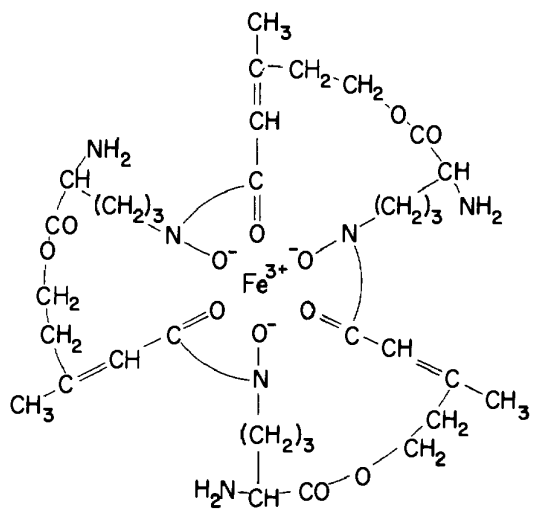

Fusigen

Figure 8. Siderochromes from Fusaria. 
this type is the recently elucidated structure of coprogen, the Nestor of the sideramine group (Figure 9) ${ }^{22}$. It is noteworthy that all those siderochromes with growth-factor activity or with no detectable biological activity are built from simple metabolites listed in Table 5 such as acetic acid, succinic

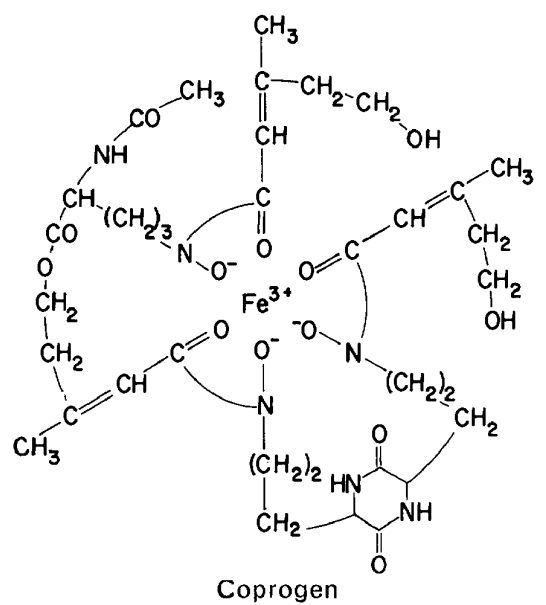

Figure 9. Sideramine from coprophilic Fungi.

acid, glycine and serine or from compounds which can be derived easily from metabolites such as 1-hydroxylamino-4-amino-butane, or 1-hydroxylamino5 -amino-pentane, or $\delta$ - $N$-hydroxyornithine. The presence and function of compounds related to mevalonic acid is still puzzling.

Table 5. Components of siderochromes

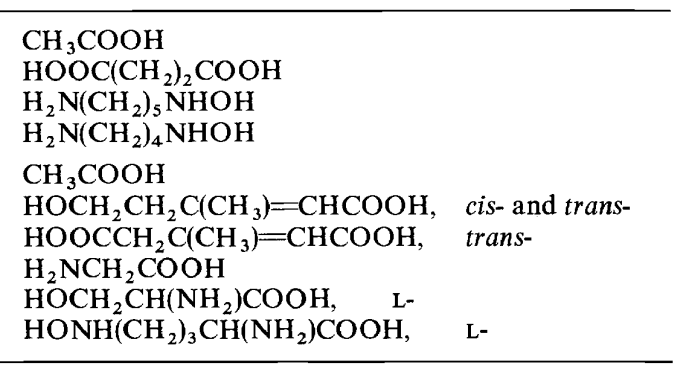

The structures of the sideromycins are very remarkable. The main component of the ferrimycin class, ferrimycin A, elucidated in our laboratory (Figure 10$)^{23}$ is a complicated acyl-derivative of the growth factor ferrioxamine B, and albomycin $\delta_{2}$ (Figure 11 ), elucidated by F. Šrm et al. ${ }^{24}$, is a derivative of an analogue of ferrichrome. Each of these antibiotics contains an additional component with a very reactive group: in ferrimycin $A_{1}$, the iminoether group, in albomycin $\delta_{2}$, the $N$-sulphonic acid ester group. As these groups seem to be essential for the antibiotic activity, it is not astonishing that the antibiotics are easily converted into their antagonists. The 
sideramines and sideromycins do not react together, so that their antagonism cannot be due to a chemical reaction. A biologically inactive solution of the antibiotics and their antagonists can be prepared, and both components can be recovered with full activity from such solutions by electrophoresis.

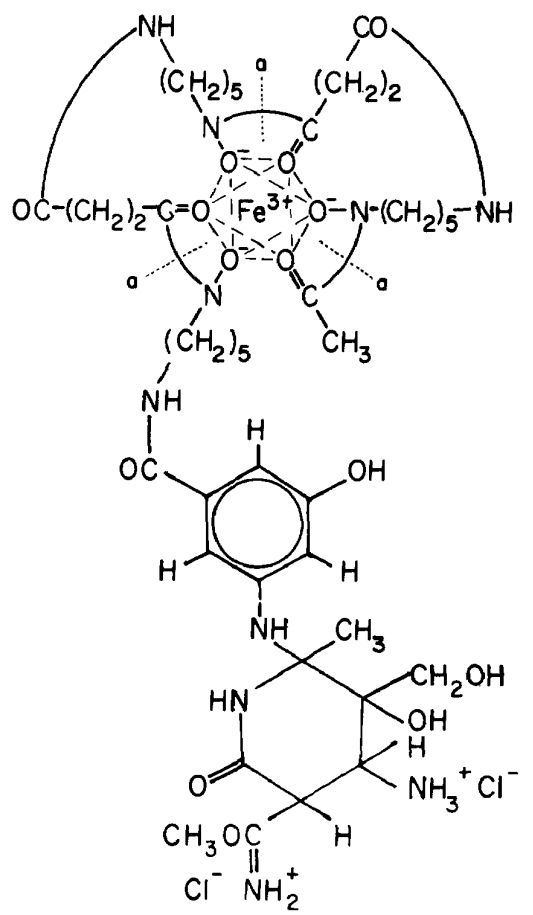

Figure 10. Ferrimycin $\mathrm{A}_{1}$.

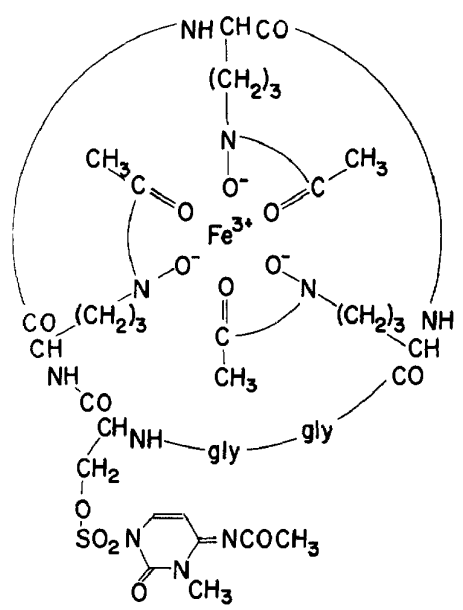

Figure 11. Albomycin $\delta_{2}$. 
Because of their instability and the fast development of resistant strains by pathological micro-organisms, sideromycins have found no application as antibiotics in medicine. However, a medicinal use has been found for the iron-free complexing agent of ferrioxamine B. This desferri-ferrioxamine B is unique in having an extremely high affinity for iron(III) ions and a rather low affinity for all other biologically important ions. This is illustrated in Table 6 by the stability constants determined by G. Schwarzenbach and co-workers ${ }^{25}$. The values for the well known synthetic complexing agent EDTA are given for comparison. L. Heilmeyer and F. Wöhler ${ }^{26}$ discovered

Table 6. Stability constants of complexes

\begin{tabular}{|c|c|c|}
\hline & Desferri-ferrioxamine B & EDTA \\
\hline & $\log K$ & $\log K$ \\
\hline $\mathrm{Fe}^{3+}$ & 30.6 & 25.1 \\
\hline $\mathrm{Ca}^{2+}$ & 2.5 & 10.6 \\
\hline $\mathrm{Co}^{2+}$ & 10.3 & 16.1 \\
\hline $\mathrm{Zn}^{2+}$ & 11.1 & 16.1 \\
\hline $\mathrm{Cu}^{2+}$ & 14.1 & 18.3 \\
\hline
\end{tabular}

that this remarkable specificity can be used for treatment of certain diseases that are accompanied by deposits of pathological iron-containing proteins in liver, spleen, pancreas etc. Such diseases as haemosiderosis or haemochromatosis are frequently progressive. Desferri-ferrioxamine B is not toxic and high doses can be used for saving the patients by removal of the pathological iron, which is then excreted in urine as ferrioxamine B. Desferriferrioxamine B can be also applied as a diagnostic tool for detecting pathological iron deposits in place of the dangerous biopsy. Normal men excrete about 2-3 mg iron per day in urine, and this amount is not changed by high doses of desferri-ferrioxamine $\mathrm{B}$. The excretion of iron in urine is increased dramatically in patients with haemosiderosis after treatment with the complexing agent. Desferri-ferrioxamine $B$ is also the life-saving antidote against poisoning by iron salts.

In the course of the development of the industrial production of desferriferrioxamine $\mathrm{B}$ it was noticed that high yields are obtained only if the micro-organism is grown in nutrition media containing very little iron. In normal media the complexing agent is produced only in minute quantities.

\section{BOROMYCIN, A UNIQUE STABLE NATURAL BORIC ACID COMPLEX $^{27}$}

The discovery of boromycin makes an amusing story. From the mycelium of a Streptomyces strain a colourless crystalline compound with a pronounced antibiotic activity towards plasmodia was isolated in our laboratories. Combustion of the antibiotic always left a little ash, which we first considered to be an impurity. It was finally identified as boric acid and as an essential part of the molecule. The puzzling fact was that, to our knowledge, 


\section{PRELOG}

we had not put any boric acid or any other boron derivative into our nutrition medium. The solution of the riddle was as simple as it was remarkable. By scrutiny of the literature we learned that practically all material of plant or animal origin contains about 50-100 p.p.m. boron, which is a trace element essential for life. The $20 \mathrm{~g}$ of soya flour per litre of our nutrition medium contains about $1 \mathrm{mg}$ boron which corresponds to about $80 \mathrm{mg}$ of the antibiotic. The remarkable fact is that the micro-organism collects practically all this boron in its mycelium as a stable lipophilic complex. A complexing agent able to perform such a task must therefore be an extremely efficient one. The investigation of its structure revealed that it is a zwitter-ion containing boric acid as an ester of a large organic molecule (Figure 12). A single nitrogen atom is contained in the amino group of the

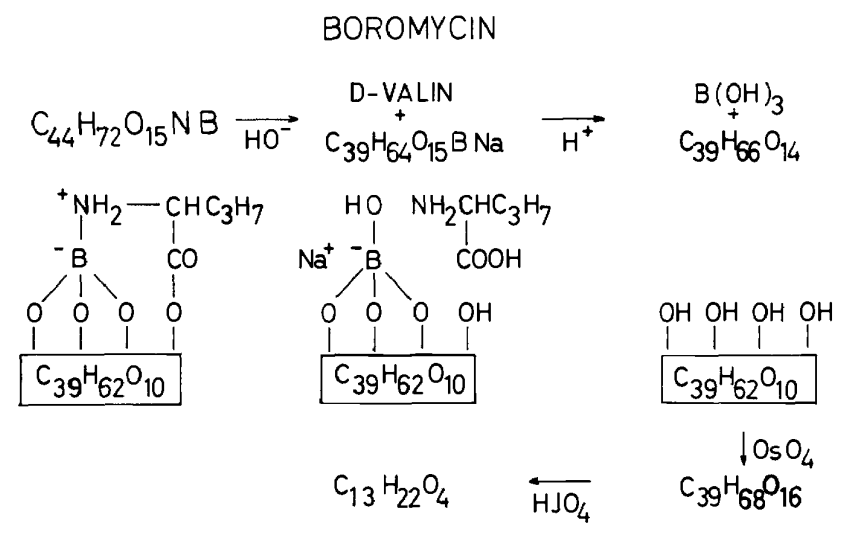

Figure 12. Degradation of boromycin.

'unnatural' D-valine, which is bound to the remaining part of the molecule by an ester group. The D-valine can be split off by careful mild alkaline hydrolysis. The so-obtained salt of a boric acid complex can now easily be hydrolysed by acids, yielding a nitrogen- and boron-free compound, which we call boromycinon. Yu. Berlin obtained by oxidation of the latter compound with osmium(vil) oxide and subsequent treatment with periodic acid an acid $\mathrm{C}_{13} \mathrm{H}_{22} \mathrm{O}_{4}$, which was studied extensively by n.m.r. and mass spectroscopy, but the remaining larger part of boromycinon obstinately resisted our degradation efforts. We prepared therefore, by hydrolysis of boromycin with caesium hydroxide, a crystalline caesium salt, presently under study by $\mathrm{x}$-ray analysis in our laboratory. The electron density maps calculated so far are too poorly resolved to permit unequivocal identification of all the atoms but the main features seem reasonably clear. The molecule appears to be rather intricate with boron inside and the lipophilic part on the surface. The skeleton of the $\mathrm{C}_{13}$ degradation product as well as certain other features found by chemical and spectroscopic methods can be recognized in the structure and we await with great interest further refinement which, we hope, will allow the unambiguous identification of all atoms in the molecule. 


\section{GENERAL CONCLUSIONS}

Some general features of the complexes investigated in our laboratories can be seen by inspecting somewhat stylized diagrams representing their structures (Figures 13, 14). All of them are spheroids with a more or less lipophilic surface and a polar core. The situation is just the reverse of the



Figure 13. Schematic representation of a macrotetrolide-alkali metal ion complex.

one in those enzyme proteins of known structure. The latter are spheroids with a more or less hydrophilic surface and a hydrophobic core containing the active site in a cleft. The complexing agents from micro-organisms are either open-chain or large-ring polydentate ligands. Additional rings, amide groups, and substituents evidently contribute not only to the stabilization of the complex but also increase the rate of its formation. A striking feature is the presence in the complexes of many-membered rings. These rings may play an important role in determining the thermodynamic stabilities and rates of formation of the complexes. Micro-organisms are certainly masters in synthesizing such unusual rings. Organic chemistry would today look quite different if the metabolites of micro-organisms had been investigated at its beginning instead of plant and animal constituents.
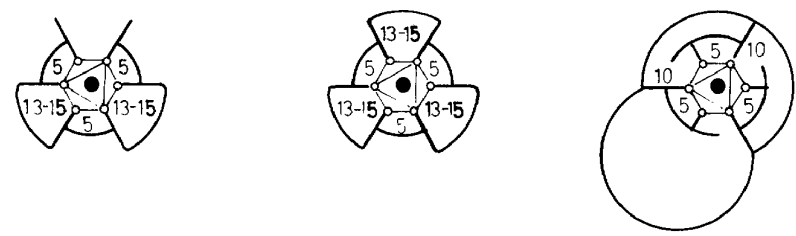

Figure 14. Schematic representation of siderochromes.

I believe that by further investigation of natural specific complexing agents we shall learn quite a lot about the construction and mechanism of action of biological tools as well as about their development in the course of evolution, and consequently, also about life itself.

\section{ACKNOWLEDGEMENT}

My sincere thanks are due to all my colleagues in Basel and in Zürich whose names appear either in the text, or in the references, or in the 


\section{PRELOG}

references in the references. I should like to express my special gratitude to Professor J. D. Dunitz for his helpful discussions.

\section{REFERENCES}

${ }^{1}$ M. M. Shemyakin, Pure Appl. Chem. This volume, page 211.

2 G. A. Snow, Bacteriol. Rev. 34, 99 (1970).

${ }^{3 a}$ T. Ikekawa, F. Iwami, H. Hirakanaka and H. Umezawa, J. Antibiotics (Japan) A, 17, 194 (1964).

${ }^{b}$ Y. Muraoka, T. Takita, K. Maeda and H. Umezawa, J. Antibiotics (Japan) A, 23, 252 (1970) and papers cited therein.

4 cf. Review articles:

${ }^{a}$ W. Keller-Schierlein and H. Gerlach in Progress in the Chemistry of Organic Natural Products, L. Zechmeister (Ed. 26, 161. Springer: Vienna and New York (1968).

${ }^{b}$ W. Keller-Schierlein, Ann. Ist. Super. Sanità, 5, 652 (1969).

$5 a$ S. N. Graven, H. A. Lardy, D. Johnson and A. Rutter, Biochemistry, 5, 1729 and 1735 (1966).

${ }^{b}$ S. N. Graven, H. A. Lardy and S. Estrada-O. Biochemistry, 6, 365 (1967). S. Estrada-O., S. N. Graven and H. A. Lardy, J. Biol. Chem. 242, 2925 (1967).

${ }^{6 a}$ B. C. Pressman, Proc. Nat. Acad. Sci., Wash., 53, 1076 (1965).

${ }^{b}$ B. C. Pressman, E. J. Harris, W. S. Jagger and J. H. Johnson, Proc. Nat. Acad. Sci., Wash., 58, 1949 (1967).

7a Z. Stefanac and W. Simon, Chimia, 20, 436 (1966).

${ }^{b}$ cf. also Review article W. Simon, L. A. R. Pioda and H.-K. Wipf, 20 Colloquium der Gesellschaft für Biologische Chemie Mosbach, 356 (1969).

8 P. Mueller and D. O. Rudin, Biochem. Biophys. Res. Commun., 26, 398 (1967).

9 L. A. R. Pioda, H. A. Wachter, R. E. Dohner and W. Simon, Helv. Chim. Acta, 50, 1373 (1967).

10 H. K. Wipf, L. A. R. Pioda, Z. Stefanac and W. Simon, Helv. Chim. Acta, 51, 377 (1968).

11 B. T. Kilbourn, J. D. Dunitz, L. A. R. Pioda and W. Simon, J. Molec. Biol. 30, 559-563 (1967).

12 R. Winkler, Thesis Göttingen-Wien (1969).

13 H.-K. Wipf and W. Simon, Biochem. Biophys. Res. Commun. 34, 707 (1969).

14 H.-K. Wipf, W. Pache, P. Jordan, H. Zähner, W. Keller-Schierlein and W. Simon, Biochem. Biophys. Res. Commun. 36, 387 (1969).

${ }^{15 a}$ L. A. R. Pioda, V. Staňkova and W. Simon, Analytical Letters, 2, 665 (1969).

${ }^{b}$ L. A. R. Pioda and W. Simon, Chimia, 23, 72 (1969).

16 C. J. Pedersen, J. Am. Chem. Soc. 92, 387 (1970).

17 B. Dietrich, J. M. Lehn and J. P. Sauvage, Tetrahedron Letters, 34, 2889 (1969).

18 cf. Review article W. Keller-Schierlein, V. Prelog and H. Zähner in Progress in the Chemistry of Organic Natural Products, L. Zechmeister (Ed.) 22, 279. Springer: Vienna (1964).

19 V. Prelog, Pure Appl. Chem. 6, 327 (1963).

20 H. Diekmann and H. Zähner, Eur. J. Biochem. 3, 213 (1967).

21 J. M. Sayer and T. F. Emery, Biochemistry, 7, 184 (1968).

22 W. Keller-Schierlein and H. Diekmann, Helv. Chim. Acta, 53, in press (1970).

${ }^{23}$ H. Bickel, P. Mertens, V. Prelog, J. Seibl and A. Walser, Tetrahedron Suppl. 8, 171 (1966).

${ }^{24 a}$ O. Mikeš, J. Turková and F. Sorm, Coll. Czech. Chem. Commun. 28, 1747 (1963).

b J. Turková, O. Mikeš and F. Šrm, Coll. Czech. Chem. Commun. 30, 118 (1965); 31, 2444 (1966).

25 G. Schwarzenbach and H. Schwarzenbach, Helv. Chim. Acta, 46, 1390 (1963).

26 L. Heilmeyer and F. Wöhler, Dtsch. Med. Wochenschr. 87, 2661 (1963).

27 R. Hütter, W. Keller-Schierlein, F. Knüsel, V. Prelog, G. C. Rodgers Jr, P. Suter, G. Vogel, W. Voser and H. Zähner, Helv. Chim. Acta, 50, 1533 (1967). 